\title{
APPLICATION OF GEOBIA TO MAP THE SEAFLOOR
}

\author{
M. Diesing a * \\ ${ }^{a}$ Centre for Environment, Fisheries and Aquaculture Science, Lowestoft, United Kingdom - markus.diesing@ cefas.co.uk
}

KEY WORDS: Marine, Seafloor, Sonar, Multibeam Echosounder, Habitat

\begin{abstract}
:
Geographic Object-Based Image Analysis (GEOBIA) has been successfully employed to map terrestrial environments. However, $71 \%$ of Earth's surface is covered by seawater and standard optical methods suitable for mapping the land surface have limited application in such environments. Application of GEOBIA to marine environments has nevertheless been attempted and can generally be subdivided into three domains: 1 . The intertidal zone and shallow subtidal zone have been mapped with optical data and application of GEOBIA in such environments can be seen as a seaward extension of terrestrial approaches. 2. Photographs of the seafloor give very detailed but spatially limited information. GEOBIA methods have been applied to classify benthic species and habitats and estimate seafloor complexity among others. 3. Due to the rapid attenuation of light in water, the method of choice to map the seafloor employs sound. Modern multi-beam echosounders map the seafloor in high detail. Such sensors measure the topography (water depth) and the strength of the returning signal (backscatter), which can be used to characterise the seafloor substrates and habitats. This contribution will focus on the application of GEOBIA to marine acoustic datasets. A generic workflow for object-based acoustic seafloor mapping will be showcased and the current state of the application of GEOBIA to marine acoustic data will be discussed.
\end{abstract}

\section{INTRODUCTION}

It has been said that the Earth's ocean is the final frontier and that we know more about the surface of Mars than the floor of our oceans. Only $5-10 \%$ of the seafloor is mapped with a resolution comparable to that on land (Wright and Heyman, 2008) due to the fact that optical methods are incapable of penetrating the water column apart from the shallowest marginal parts of the world ocean. Unsurprisingly, there have been limited attempts so far to apply GEOBIA to marine data sets with the aim to map the seafloor.

Marine Object-Based Image Analysis (MOBIA), here defined as the application of GEOBIA to marine data sets with the aim to map the seafloor geomorphology, geology and habitats, is a nascent science discipline, but most advanced where optical remote sensing imagery collected from satellites and remotely operated aircraft systems ('drones') has been utilised to map intertidal and shallow subtidal habitats. Among the most frequently mapped habitats are mangroves (Conchedda et al., 2008; Heumann, 2011; Wang et al., 2004), saltmarsh (Moffett and Gorelick, 2013; Ouyang et al., 2011), seagrass (Lathrop et al., 2006; Lyons et al., 2012; Roelfsema et al., 2014) and coral reefs (Benfield et al., 2007; Knudby et al., 2011; Phinn et al., 2012).

Seafloor photographic images, collected from various platforms, such as drop-frames, benthic sledges, remotely operated vehicles and autonomous underwater vehicles, might be interpreted separately or stitched together to derive georeferenced photo-mosaics. Such image data sets could be analysed with GEOBIA methods to map habitats and derive (semi-)quantitative information (e.g. seafloor complexity); however a significant drawback is the very limited footprint on the order of $1 \mathrm{~m}^{2}$ to several $100 \mathrm{~m}^{2}$ and few examples exist in the peer-review literature (Lacharité et al., 2015).
The preferred method to map the seafloor in sufficient detail utilises sound rather than light, as sound is much less attenuated and travels over significant distances in the water column. Modern multibeam echosounders (MBES) survey the seafloor in high detail and typically measure two parameters: the travel time of the sound from the transducer to the seafloor and back to the receiver, which can be converted to water depths and the intensity of the returned signal, commonly known as backscatter strength. From the depth data, it is possible to construct detailed digital elevation models and derive secondary variables, such as seafloor slope and rugosity. The backscatter strength is influenced by various factors, such as the geometry of the sonar-target system, the physical characteristics and the intrinsic nature of the seafloor (Blondel, 2009), but yields an interpretable acoustic image of the makeup of the seafloor surface. It is mainly this kind of imagery that has proved most useful for mapping seafloor sediments and habitats (Brown et al., 2011). Due to the fact that MBES typically survey with one acoustic frequency those backscatter images are essentially limited to one band.

The resolution of acoustic seafloor imagery is dependent on the beam width and the water depth. Typical shallow water MBES collect data with a spatial resolution of c. $1 \mathrm{~m}$ to $5 \mathrm{~m}$. Features of interest are typically larger than that (H-resolution case) and object-based approaches are appropriate under these circumstances (Blaschke et al., 2014). Since Lucieer's (2008) paper on object-based mapping of benthic marine habitats, uptake of GEOBIA methods has been slow but is currently accelerating with studies published in the peer-review literature (e.g. Diesing et al., 2014; Lucieer and Lamarche, 2011; Montereale Gavazzi et al., 2016) and presented at conferences. This contribution will showcase a generic workflow for categorical seafloor mapping based on acoustic data sets and ground-truth observations.

\footnotetext{
* Corresponding author
} 


\section{GENERIC WORKFLOW}

Because the interpretation of seafloor acoustic imagery is significantly less unequivocal than optical images of the land surface, ground-truth observations are usually required. These might be seafloor still images interpreted with respect to substrate or habitat type or physical samples of the seafloor taken with grab samplers. Collected sediment samples might be analysed for their grain-size distribution and content of benthic species and classified accordingly. The need for samples does mean that the classification process is typically sample-based rather than rule-based. A generic workflow is shown in Figure 1.

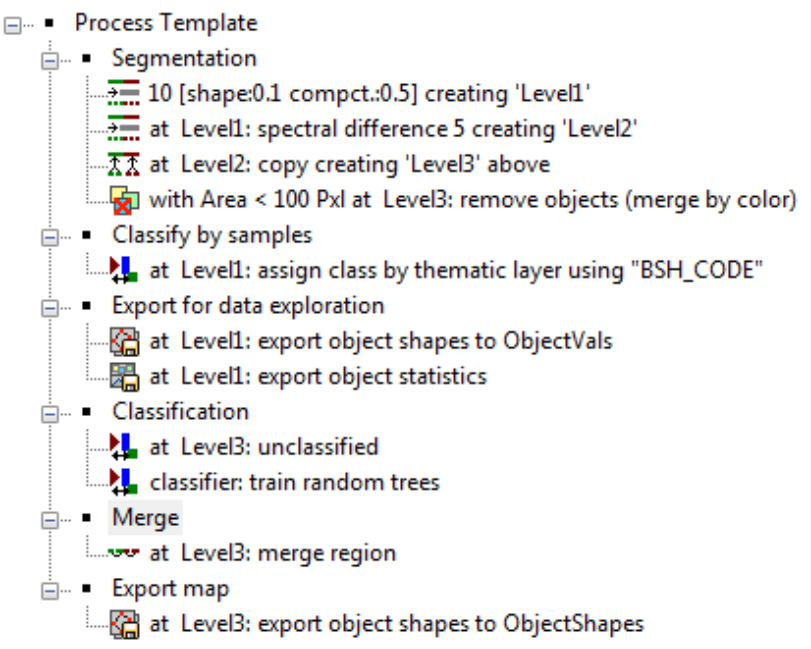

Figure 1. Generic workflow for acoustic seafloor mapping.

\subsection{Segmentation}

Segmentation is typically carried out with the multiresolution segmentation algorithm utilising suitable image layers. The scale parameter might be estimated via the Estimation of Scale Parameter tool (Drăguţ et al., 2010) or via visual assessment of the segmentation results. Further segmentation steps might include merging of objects with the spectral difference algorithm and removal of small objects of a size below a defined minimum mapping unit.

\subsection{Classification by samples}

Ground-truth information brought into the project as a thematic layer (shape file) is utilised to classify image objects that coincide with these samples. Image object features that are deemed potentially useful for further classification are then selected and feature values extracted for every classified object.

\subsection{Feature selection}

We have developed a browser-based tool utilising Shiny, a web application framework for $\mathrm{R}$, to select important and remove correlated features. Feature selection is carried out with the Boruta algorithm (Kursa and Rudnicki, 2010) and correlated features can be identified with a correlation matrix.

\subsection{Data exploration/model building}

Additionally, the tool allows the user to display the data as box plots and density curves for the selection of suitable thresholds for classification. Alternatively, Conditional Inference (CI) analysis (Hothorn et al., 2006) might be carried out. The resulting decision tree (Figure 2) is easily translatable into an eCognition rule-set.

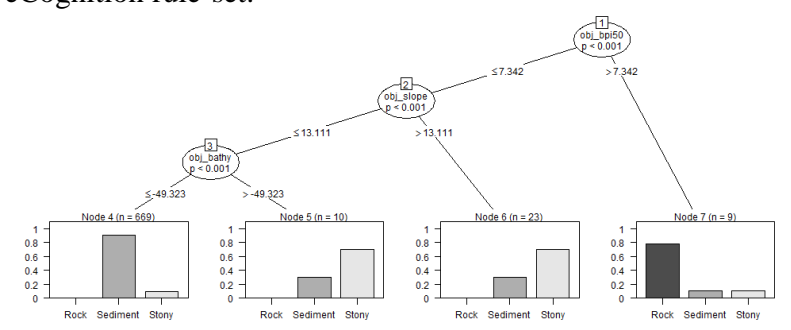

Figure 2. Example of CI decision tree that can be translated into a rule-set.

\subsection{Classification}

Classification in eCognition might be carried out in three different ways, a) by applying simple rules and thresholds as derived by data exploration, b) by translating the CI decision tree into a rule-set or c) by utilising the implemented machine learning algorithms (e.g. Random Forest, Breiman, 2001). Once acceptable results are achieved, image objects are merged by class and the final results exported as a shape file.

\section{DISCUSSION}

Automated and repeatable acoustic seafloor classification is still in its infancy, but progress could be accelerated by learning from terrestrial remote sensing (Diesing et al., 2016). The same is true for the application of GEOBIA to acoustic data. It is encouraging to see the increasing amount of studies presented at conferences such as GeoHab (geohab.org). However, more research is needed to fully assess and exploit the true potential of GEOBIA in relation to acoustic seafloor mapping. Only a limited amount of features available for classification is typically utilised. These are most frequently object statistics and to a lesser extent texture and shape features. There has been little usage of object relationships and the concept of hierarchy in landscapes (Burnett and Blaschke, 2003), represented as segmentations at different levels, has hardly been investigated so far.

A limiting factor in acoustic seafloor mapping is the missing spectral resolution of backscatter data, which typically consists of one band. Hence, it is not possible to derive band ratios or exploit spectral signatures. The potential for improved seafloor classification with 3-band acoustic backscatter data has recently been demonstrated (Hughes-Clarke, 2015; Tamsett et al., 2016) and it is hoped that multi-spectral MBES will become the standard in seafloor mapping.

\section{ACKNOWLEDGEMENTS}

This work was funded by the Cefas Research and Development Fund.

\section{REFERENCES}

Benfield, S.L., Guzman, H.M., Mair, J.M., Young, J. a. T., 2007. Mapping the distribution of coral reefs and associated sublittoral habitats in Pacific Panama: a comparison of optical satellite sensors and classification methodologies. Int. J. Remote Sens. 28, 5047-5070. doi:10.1080/01431160701258062

Blaschke, T., Hay, G.J., Kelly, M., Lang, S., Hofmann, P., Addink, E., Queiroz Feitosa, R., van der Meer, F., van der Werff, H., van Coillie, F., Tiede, D., 2014. Geographic Object- 
Based Image Analysis - Towards a new paradigm. ISPRS J. Photogramm. Remote Sens. 87, 180-191.

Blondel, P., 2009. The handbook of sidescan sonar. Springer, Berlin, Heidelberg, New York.

Breiman, L., 2001. Random Forests. Mach. Learn. 45, 5-32.

Brown, C.J., Smith, S.J., Lawton, P., Anderson, J.T., 2011. Benthic habitat mapping: A review of progress towards improved understanding of the spatial ecology of the seafloor using acoustic techniques. Estuar. Coast. Shelf Sci. 92, 502520. doi:10.1016/j.ecss.2011.02.007

Burnett, C., Blaschke, T., 2003. A multi-scale segmentation/object relationship modelling methodology for landscape analysis. Ecol. Modell. 168, 233-249.

Conchedda, G., Durieux, L., Mayaux, P., 2008. An object-based method for mapping and change analysis in mangrove ecosystems. ISPRS J. Photogramm. Remote Sens. 63, 578-589. doi:10.1016/j.isprsjprs.2008.04.002

Diesing, M., Green, S.L., Stephens, D., Lark, R.M., Stewart, H.A., Dove, D., 2014. Mapping seabed sediments: Comparison of manual, geostatistical, object-based image analysis and machine learning approaches. Cont. Shelf Res. 84, 107-119.

Diesing, M., Mitchell, P., Stephens, D., 2016. Image-based seabed classification: what can we learn from terrestrial remote sensing? ICES J. Mar. Sci. doi:10.1093/icesjms/fsw118

Drăguţ, L., Tiede, D., Levick, S.R., 2010. ESP: a tool to estimate scale parameter for multiresolution image segmentation of remotely sensed data. Int. J. Geogr. Inf. Sci. 24, 859-871.

Heumann, B.W., 2011. An object-based classification of mangroves using a hybrid decision tree-support vector machine approach. Remote Sens. 3, 2440-2460. doi:10.3390/rs3112440

Hothorn, T., Hornik, K., Zeileis, a, 2006. party: A Laboratory for Recursive Part (y) itioning. R Packag. version 0.9-0, URL http//CRAN. R-project. org. doi:10.1.1.151.2872

Hughes-Clarke, J.E., 2015. Multispectral Acoustic Backscatter from Multibeam, Improved Classification Potential, in: United States Hydrographic Conference 2015. National Harbor, MD, USA, pp. 1-18.

Knudby, A., Roelfsema, C., Lyons, M., Phinn, S., Jupiter, S., 2011. Mapping Fish Community Variables by Integrating Field and Satellite Data, Object-Based Image Analysis and Modeling in a Traditional Fijian Fisheries Management Area. Remote Sens. 3, 460-483.

Kursa, M., Rudnicki, W., 2010. Feature selection with the Boruta Package. J. Stat. Softw. 36, 1-11.

Lacharité, M., Metaxas, A., Lawton, P., 2015. Using objectbased image analysis to determine seafloor fine-scale features and complexity. Limnol. Oceanogr. Methods 13, 553-567. doi:10.1002/lom3.10047

Lathrop, R.G., Montesano, P., Haag, S., 2006. A Multi-scale Segmentation Approach to Mapping Seagrass Habitats Using Airborne Digital Camera Imagery. Photogramm. Eng. Remote Sens. 72, 665-675. doi:10.14358/PERS.72.6.665
Lucieer, V., Lamarche, G., 2011. Unsupervised fuzzy classification and object-based image analysis of multibeam data to map deep water substrates, Cook Strait, New Zealand. Cont. Shelf Res. 31, 1236-1247. doi:10.1016/j.csr.2011.04.016

Lucieer, V.L., 2008. Object-oriented classification of sidescan sonar data for mapping benthic marine habitats. Int. J. Remote Sens. 29, 905-921.

Lyons, M.B., Phinn, S.R., Roelfsema, C.M., 2012. Long term land cover and seagrass mapping using Landsat and objectbased image analysis from 1972 to 2010 in the coastal environment of South East Queensland, Australia. ISPRS J. Photogramm. Remote Sens. 71, 34-46. doi:10.1016/j.isprsjprs.2012.05.002

Moffett, K.B., Gorelick, S.M., 2013. Distinguishing wetland vegetation and channel features with object-based image segmentation. Int. J. Remote Sens. 34, 1332-1354. doi:10.1080/01431161.2012.718463

Montereale Gavazzi, G., Madricardo, F., Janowski, L., Kruss, A., Blondel, P., Sigovini, M., Foglini, F., 2016. Evaluation of seabed mapping methods for fine-scale classification of extremely shallow benthic habitats - Application to the Venice Lagoon, Italy. Estuar. Coast. Shelf Sci. 170, 45-60. doi:10.1016/j.ecss.2015.12.014

Ouyang, Z.T., Zhang, M.Q., Xie, X., Shen, Q., Guo, H.Q., Zhao, B., 2011. A comparison of pixel-based and objectoriented approaches to VHR imagery for mapping saltmarsh plants. Ecol. Inform. 6, 136-146. doi:10.1016/j.ecoinf.2011.01.002

Phinn, S.R., Roelfsema, C.M., Mumby, P.J., 2012. Multi-scale, object-based image analysis for mapping geomorphic and ecological zones on coral reefs. Int. J. Remote Sens. 33, 37683797. doi:10.1080/01431161.2011.633122

Roelfsema, C.M., Lyons, M., Kovacs, E.M., Maxwell, P., Saunders, M.I., Samper-Villarreal, J., Phinn, S.R., 2014. Multitemporal mapping of seagrass cover, species and biomass: A semi-automated object based image analysis approach. Remote Sens. Environ. 150, 172-187. doi:10.1016/j.rse.2014.05.001

Tamsett, D., McIlvenny, J., Watts, A., 2016. Colour Sonar: Multi-Frequency Sidescan Sonar Images of the Seabed in the Inner Sound of the Pentland Firth, Scotland. J. Mar. Sci. Eng. 4, 26. doi: $10.3390 /$ jmse 4010026

Wang, L., Sousa, W.P., Gong, P., 2004. Integration of objectbased and pixel-based classification for mapping mangroves with IKONOS imagery. Int. J. Remote Sens. 25, 5655-5668. doi:10.1080/014311602331291215

Wright, D.J., Heyman, W.D., 2008. Introduction to the Special Issue: Marine and Coastal GIS for Geomorphology, Habitat Mapping, and Marine Reserves. Mar. Geod. 31, 223-230.

Revised June 2016 